\title{
A modelling approach to reduce the simulation time of building stock models
}

\author{
Rana Mahmoud $^{1}$, Eline Himpe ${ }^{1}$, Marc Delghust ${ }^{1}$, Jelle Laverge ${ }^{1}$ \\ ${ }^{1}$ Building Physics research group, \\ Department of Architecture and Urban Planning, \\ Faculty of Engineering and Architecture, \\ Ghent University, Ghent, Belgium
}

\begin{abstract}
Modelling of heating and cooling demand of the building stock is valuable for estimating the sizing of HVAC technologies. However, designer faces oversizing problems as they rely on their experiences or the use of single zone simulations. Multizone building stock models that take into consideration the interaction between the different zones' profiles, and building envelope properties to obtain reliable estimations is needed. Simulations of large amount of building stock models require extensive computation and simulation time. Therefore, we developed multi-zone generic modelling approach that allows modelling and simulation of large population of building stock cases in shorter time. The approach relies on splitting the building into modules that are modelled separately and of which the simulation results are aggregated afterwards. This paper investigates the strengths and limitations of the proposed approach on a selected case-study building by comparing it to classical modelling approaches. A reduction of $80 \%$ in simulation time was achieved. The hourly heating and cooling demands for the proposed and classical approaches reached a lowest deviation of $1.4 \%$ for buildings with higher U-values, and one set temperature.
\end{abstract}

\section{Introduction}

Building stock modelling has high potential for assessing the energy demand in existing buildings in order to evaluate energy performance of buildings (Dascalaki, et al. 2011) and new retrofit schemes (Sandberg, et al. 2016). Besides, it is used to investigate the potential energy savings and CO2-reduction strategies (Ballarini 2014; Kavgic 2010; Tuominen 2014). In conclusion, building stock energy modelling is a powerful approach to assess the effectiveness and feasibility of energy efficiency and renewable energy measures for the building stock as a whole, and for segments of buildings with similar properties. It may be used to offer policy makers guidance regarding future regulations, and actors in the building and energy sector to decide which solutions to develop and apply for various segments in the building stock.

An example is the hybridGEOTABS project, that looks at the development, demonstration and exploitation of a hybrid combination of GEOTABS (geothermal heat pumps combined with thermally activated building systems) and secondary systems for the heating and cooling of buildings (HybridGeotabs Project 2016). In this project, using building stock modelling, the feasibility and energy reduction potential of the hybridGEOTABS technology for various building typologies in various EU climates is investigated, and recommendations for policy and market deployment will be formulated. Another application of energy-use simulations of the variety of buildings in the building stock relies on the generation of energy demand outputs (e.g. heating and cooling load duration curves). They are a valuable source of information for HVAC-designers aiming to provide a better system sizing for their clients. In the hybridGEOTABS project, detailed heating and cooling demand simulations for the building stock are used to develop an optimized sizing of hybridGEOTABS, while avoiding case-by-case simulations of the building.

To acquire accurate heating and cooling demand, the different zonal requirements based on different functions and profiles (e.g. Internal gains profiles, heating and cooling zone requirements) and its interaction with the building envelope properties should be considered. Thus, multi-zone dynamic models are needed. Bottom up modelling approach could be used, as it considers the use of the building properties and the physical characteristics of the building stock. Bottom-up modelling of the building stock requires an extensive database of the characteristics and the physical properties of buildings (Shorrock 1997; Wang 2018; Kavgic 2010). Gathering the building stock data is considered difficult because the data is either scattered or, due to the privacy of the information. In this research the Energy Performance of Building data EPB regional database from Flanders is used as a source for the building stock database (VEAEPB database 2016). The data include general geometrical and building physical properties of the individual buildings. This information is not sufficient to develop detailed multi-zone energy simulation models. A fitting process that allows transforming the general geometrical data into multi-zone building models was developed by Delghust (2015) for residential buildings. In this research the fitting approach is implemented and further developed for office buildings, starting from a multi-zone archetype office building.

When modelling the variety of individual buildings in the building stock, one will typically end up with a very high amount of building cases to simulate. When simulating all these cases using a dynamic multi-zone BES-model, this 
results in high computation times. For example, the database used in this study accounts for 40176 cases. The estimated time required to simulate all these cases is about 5 months. Adding to this the time needed to model each case, it is concluded that a generic yet accurate modelling approach that allows to reduce the simulation time is needed. In this research, a modelling process is developed that relies on splitting the building into modules that are modelled separately and of which the simulation results are aggregated afterwards.

In this paper we present (1) the fitting process that translates the building stock data into input data for multizone building models, and (2) the approach proposed for modelling the building stock. Furthermore, we investigate the strengths and limitations of the proposed modelling approach by comparing it to a full model of the building classical modelling approach). In the validation, a casestudy building is used, with varying temperature settings and building envelope properties. The different models are compared using absolute difference and normalized root mean square error (RMSE).

\section{Modelling method}

\section{Building stock fitting process}

Building stock data for office buildings was gathered from the Flemish EPB-database (VEA-EPB database 2016). The available data are general geometrical data, such as the building volume, gross surface area, heat loss surface area and window-to-wall ratio. To go from these data to a multi-zone building model, the data is fitted to an archetype form (Delghust 2015). First, an archetype multi-zone building model is created that represents the typical building functions and spaces of the office building typology. This archetype geometry is parametrized to fit the gathered building stock geometrical data. Thus, the archetype building model is stretched to the dimensions of the various buildings in the stock. This is achieved by choosing a modular form and combination of building zones that can be parameterized. The archetype typical floor plan is divided into 5 zones with typical office functions: meeting rooms, single offices, landscape offices, restaurants and service areas.

The building geometry is defined by variables such as the length, width, height and number of floors, that are functions of the building area, volume and heat loss surface area available in the building stock data. The building shape consists of two cuboid forms (A and B) that are attached to each other via one surface as in Figure 1. The building width (a) is fixed to 15.5 meters, representing two office zones with $6 \mathrm{~m}$ width, facing each other with a 2.5 meters corridor in between (the dimensions are based on the standard Neufert (2000) for office buildings. The first form (A) has (n) number of floors and is assumed between 2 and 10 floors, which is representative for office buildings in Flanders. Building floor height $\left(\mathrm{h}_{1}\right)$ is derived from the building input data by dividing the volume by the gross floor area.

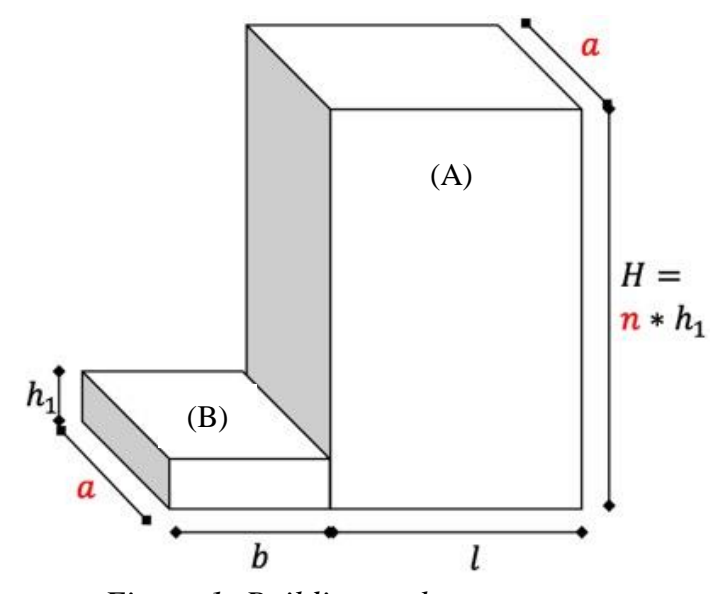

Figure 1: Building archetype geometry

The building length (1) is a variable that is parametrized based on each individual case in the building stock. The building height is a function of the number of floors (n). The second form (B) has a fixed height of one floor $\left(\mathrm{h}_{1}\right)$ and has (b) variable length. As such this additional form (B) allows to take up the variations in building volume, heat loss area and gross floor area in the building stock data that cannot be taken up by the main form A.

\section{Modelling approach}

The fitting process results in a multi-zone building geometry for each case in the building stock, and is the basis of the BES-model for each case. Together with a number of variations in building physical parameters, about 40176 office cases need to be simulated, which would take about 6 months of simulation time. To reduce the simulation time, a more generic modelling approach is investigated based on the following assumptions. We consider that all the building floors has TABS installed, hence, the floors are thermally separated with no heat transfer between the floors. This is translated in the model as following: there is no heat transfer between the ground floor and the intermediate floors in the building, or between the last floor and the intermediate floors. Thus, for cases where the number of floors is higher than three, a separated floor modelling approach is used. In such cases, the building is split into its floors and we model 3 separated models, each represent a building floor (see Figure 2). The building ground floor is modeled with an adiabatic ceiling so there is no heat flow between the ground floor and the intermediate floors. The intermediate floor is modelled with an adiabatic floor and ceiling, so there is no heat exchange with the surrounding floors. Likewise, the last floor is modelled with an adiabatic floor. The total heating and cooling demand of the whole building can be calculated by summing up the heating and cooling demands Q1, Q2 and Q3, where the demand of the intermediate floor will be multiplied by (i), the number of intermediate floors in the building, as in Equation (1)

$$
\mathrm{Q}_{\text {demandtotal }}=\mathrm{Q} 1+(\mathrm{Q} 2 * \mathrm{i})+\mathrm{Q} 3 \quad \text { equation }(1)
$$




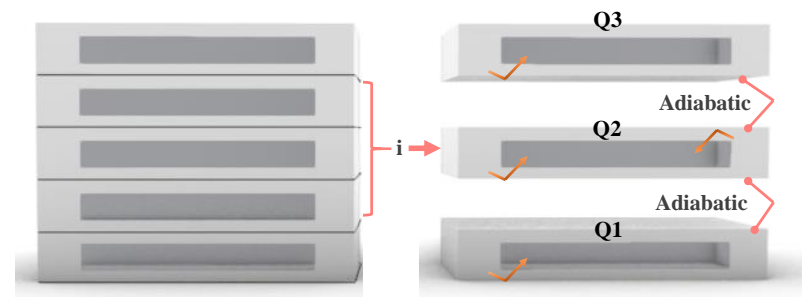

Figure 2: Building stock modelling approach

\section{Validation method}

\section{Case-study office building}

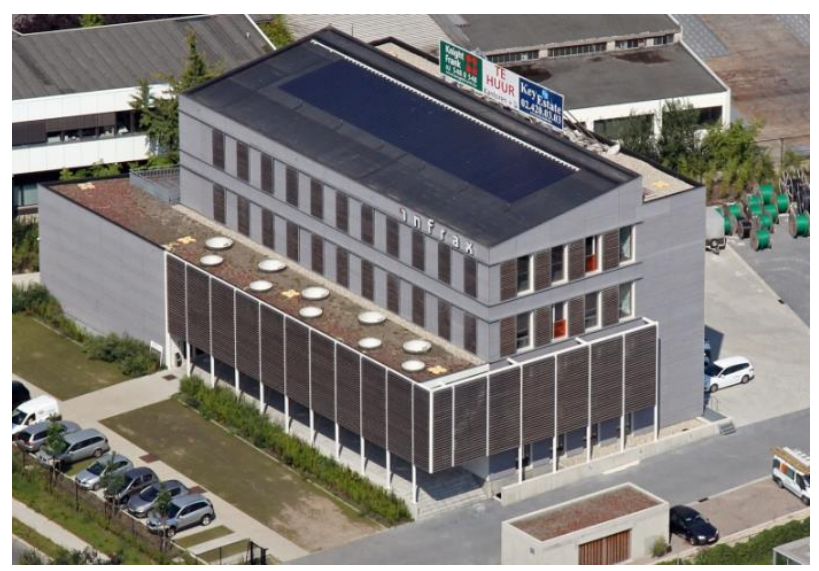

Figure 3: Photo of the case study building used in modelling, showing the geometrical form.

To validate the presented modelling approach, a reference office building was selected. The case study office building is located in Dilbeek, Belgium Figure 3 . The building geometrical properties are presented in Table 1 and the layout is shown in Figure 4.

Table 1: Reference building geometrical variables

\begin{tabular}{ll}
\hline Building design Variables & \\
\hline Area $\left[\mathrm{m}^{2}\right]$ & 2538 \\
\hline Volume $\left[\mathrm{m}^{3}\right]$ & 10413.3 \\
Heat loss surface area $\left[\mathrm{m}^{2}\right]$ & 3236.6 \\
Height $[\mathrm{m}]$ & 16.3 \\
Number of floors & 4 \\
Window to wall ratio $[\%]$ & 14.00 \\
\hline
\end{tabular}

By applying the presented fitting process to fit the reference building geometry to the proposed archetype form from Figure 1, two possible solutions were obtained. The first solution has 4 floors, the length (1) is $39.7 \mathrm{~m}$, and the length (b) is $4.96 \mathrm{~m}$ as in Figure 5. For the second solution, the number of floors is 10 , and length (1) is 15.9 $\mathrm{m}$, and (b) is $4.07 \mathrm{~m}$. We selected the first solution for testing the validity of our model as it has the same number of floors as the real reference case.
Building energy simulation models

BES-models were created in Modelica modelling language, using the Dymola tool and the OpenIDEAS library (Baetens 2015).

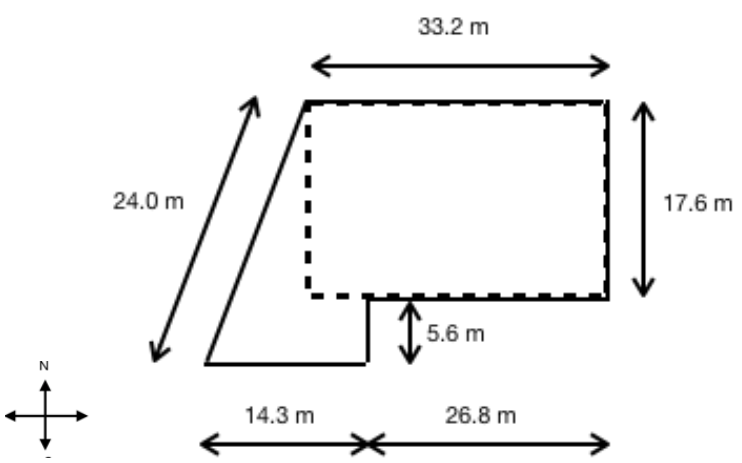

Figure 4: Reference layout dimensions for model (A)

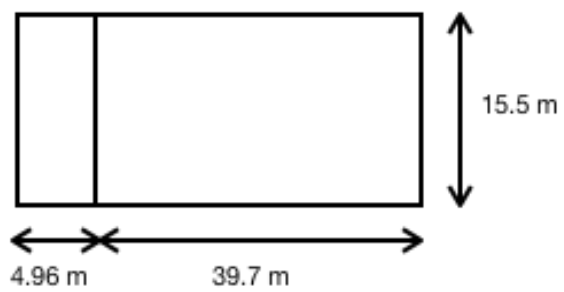

Figure 5: Fitted layout dimensions for models $(B \& C)$

The BES-model is made of different classes, each defining a model component. The first class is the building structure that defines the building geometry with different zones. Each zone is defined by the number of surfaces, such as walls, floor, windows, and internal walls. These surfaces are connected to adjacent zones. For each surface type, the thickness of the building materials is based on the identified U-value. The second class contains the heating and cooling system. For this we have used an ideal heating system with different temperature settings. The third class defines all building geometrical variables. An external shading system was implemented with an on-off controller for all models. The larger façade is facing north. The shading system is on when solar irradiation is higher than $250 \mathrm{~W} / \mathrm{m}^{2}$ on the external window surfaces. Neither ventilation system, nor internal heat gains were taken into consideration in the models at this stage.

Three models were used for the validation process. Model (A) is a detailed BES-model based on the real office building(reference case). The model is created by Cupeiro Figueroa (2018). Model (B) and model (C) are simplified models, resulted from the implemented fitting process to fit into the form shown in Figure 1. Model (B) is a model where the four floors are coupled. Model (C) is a model with three separated floors as in Figure 2, in this model the intermediate floor energy demand simulation output will be multiplied by 2 . Model (A) has four floors divided into 27 zones similar to the real reference building. 
Model(B) has four floors divided into 21 zones, where volume (A) as shown in Figure 1 has 20 zones spread over four floors each of 5 zones, while volume (B) has one zone. On the other hand, model (C) has three separated models, each represents a floor with a total of 16 zones. The zones follow the same division as model (B) with 15 Zones divided on 3 floors, while one attached zone contained in volume (B). The zones of the three models represent the following functions: meeting rooms, landscape offices, closed single offices, restaurant and service zones such as stairs, kitchen, bathrooms, copy and printing rooms.

\section{Results and discussion}

The heating and cooling hourly demand simulations of the three models A, B and C were compared to see to what extent the models are in agreement. An ideal heating/cooling system is supposed and the agreement is checked for two setpoint temperature settings: one setpoint temperature $\left(\mathrm{T}_{\mathrm{S}}=22.5^{\circ} \mathrm{C}\right)$ for all zones, or different setpoint temperatures for heating $\left(\mathrm{T}_{\mathrm{H}}=20.0^{\circ} \mathrm{C}\right)$ and cooling $\left(\mathrm{T}_{\mathrm{C}}=25.0^{\circ} \mathrm{C}\right)$. All three models have the same building physical properties. Regarding the Uvalues, for roof $U_{\text {roof }}=0.15\left[\mathrm{~W} / \mathrm{m}^{2} . \mathrm{K}\right]$, for external walls $\mathrm{U}_{\text {wall }}=0.18\left[\mathrm{~W} / \mathrm{m}^{2} . \mathrm{K}\right]$ and for ground floors $\mathrm{U}_{\text {floor }}=0.22$ $\left[\mathrm{W} / \mathrm{m}^{2} . \mathrm{K}\right]$. The air tightness of the building is 1.3 at $\mathrm{n} 50$ value $(1 / \mathrm{h})$ and the glazing has $\mathrm{U}$-value of $1.0\left[\mathrm{~W} / \mathrm{m}^{2} . \mathrm{K}\right]$.

The three models were compared to see the difference in terms of simulation time as in Table 2 . Model(A) has the highest simulation time, since it is more detailed, while model (B) is lower than model (A) due to reduced number of zones and model (C) has the lowest simulation time. The simulation time of model (C) represents the sum of the simulation time of the three separated models of each floor. Model (C) has $75 \%$ less simulation time than model (B) since each floor has only 5 zones, therefore less time is needed for solving the physical model equations. A significant reduction in simulation time is thus possible using the proposed modular approach. By applying this approach, the simulation time for the 40176 cases can be reduced from 6 months to 1 month of simulations equivalent to $80 \%$ reduction of simulation time.

Table 2: Comparison between models in terms of simulation time

\begin{tabular}{|c|c|c|c|}
\hline & Model(A) & Model (B) & Model (C) \\
\hline $\begin{array}{c}\text { Simulation Time } \\
\text { [Sec] }\end{array}$ & 385 & 195 & 49 \\
\hline
\end{tabular}

Figure 6 and Figure 7 shows the hourly heating and cooling demand simulations for one year for the three models, and for the two set point temperatures respectively. Model (A) has the highest hourly heating demand during winter and the lowest cooling demand in summer.

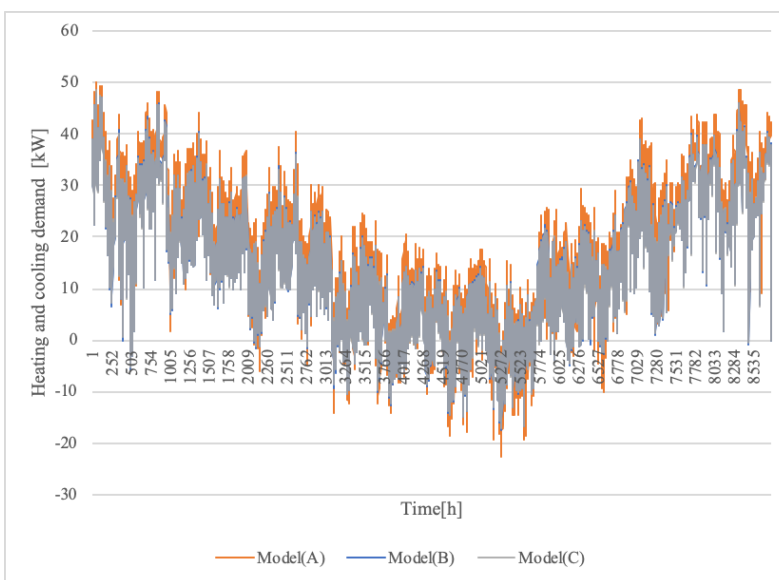

Figure 6: Comparison between hourly heating and cooling demand at $T s=22.5^{\circ} \mathrm{C}$ for models $(A),(B)$ and

(C)

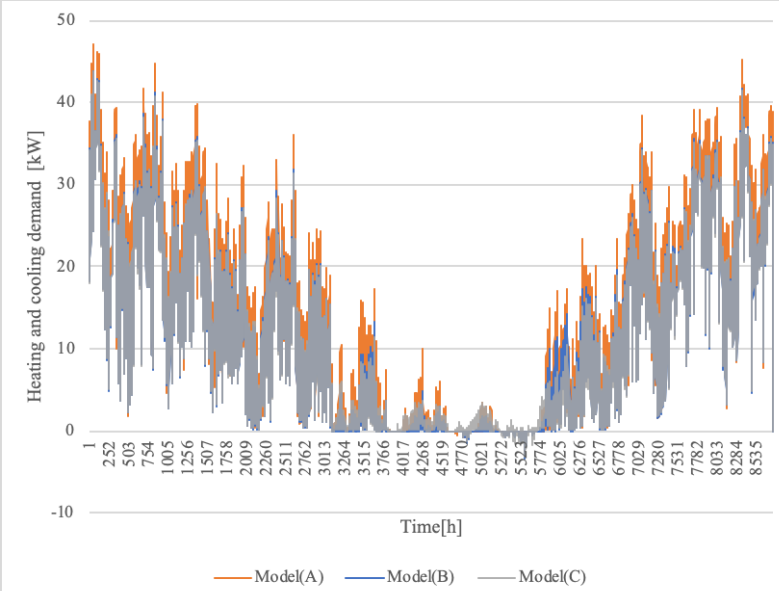

Figure 7: Comparison between hourly heating and cooling demand at $T_{H}=20^{\circ} \mathrm{C}, T_{C}=25^{\circ} \mathrm{C}$ for the $\operatorname{model}(A),(B)$ and $(C)$

Models (B) and (C) behave very similar to each other in terms of hourly demands. The building is heat dominated rather than cooling. Table 3 and Table 4 shows comparison of the annual heating and cooling demand between the three models per square meter and there absolute difference. The heating demand reaches a difference of $15 \%$ between models $\mathrm{A}$ and $\mathrm{B}$, same for models $\mathrm{A}$ and $\mathrm{C}$. For cooling, the overall cooling demand is very low: below $1 \mathrm{kWh} / \mathrm{m}^{2} /$ year for $\mathrm{T}_{\mathrm{H}}$ and $\mathrm{T}_{\mathrm{C}}$ setpoints and below $2.5 \mathrm{kWh} / \mathrm{m}^{2} /$ year for $\mathrm{T}_{\mathrm{S}}$ setpoint. The cooling load for $\mathrm{T}_{\mathrm{H}}$ and $\mathrm{T}_{\mathrm{C}}$ is lower due to the free-floating temperature between the temperature bounds of $20.0^{\circ} \mathrm{C}$ and $25.0^{\circ} \mathrm{C}$ allowing for lower cooling demand as the ideal heating and cooling system is turned off. When comparing the models $\mathrm{B}$ and $\mathrm{C}$, that do have identical form and zone distribution per floor, the difference for space heating and cooling is very small lower than $1 \%$. As a preliminary conclusion, the new modelling approach works well for this case-study. These findings hold for both temperatures set point scenarios. 
Table 3: Comparison between the annual heating and cooling demand per square meter for the models $(A),(B)$ and $(C)$

\begin{tabular}{ccccccc}
\hline & \multicolumn{2}{c}{ Model(A) } & \multicolumn{2}{c}{ Model(B) } & \multicolumn{2}{c}{ Model(C) } \\
\hline & $\begin{array}{c}\text { Heating } \\
\text { demand } \\
{\left[\mathrm{kWh} / \mathrm{m}^{2} . \mathrm{a}\right]}\end{array}$ & $\begin{array}{c}\text { Cooling } \\
\text { demand } \\
{\left[\mathrm{kWh} / \mathrm{m}^{2} . \mathrm{a}\right]}\end{array}$ & $\begin{array}{c}\text { Heating } \\
\text { demand } \\
{\left[\mathrm{kWh} / \mathrm{m}^{2} . \mathrm{a}\right]}\end{array}$ & $\begin{array}{c}\text { Cooling } \\
\text { demand } \\
{\left[\mathrm{kWh} / \mathrm{m}^{2} . \mathrm{a}\right]}\end{array}$ & $\begin{array}{c}\text { Heating } \\
\text { demand } \\
{\left[\mathrm{kWh} / \mathrm{m}^{2} . \mathrm{a}\right]}\end{array}$ & $\begin{array}{c}\text { Cooling } \\
\text { demand } \\
{\left[\mathrm{kWh} / \mathrm{m}^{2} . \mathrm{a}\right]}\end{array}$ \\
\hline $\mathrm{T}_{\mathbf{H}=20.0^{\circ} \mathrm{C} \& \mathrm{~T}_{\mathrm{C}}=25.0^{\circ} \mathrm{C}}^{47.91}$ & 0.004 & 40.69 & 0.04 & 40.80 & 0.05 \\
$\mathrm{TS}=22.5^{\circ} \mathrm{C}$ & 64.52 & 2.35 & 54.58 & 2.08 & 54.56 & 2.03 \\
\hline
\end{tabular}

Table 4: Comparison between the absolute difference of the annual heating and cooling demand per square meter for the models $(A),(B)$ and $(C)$

\begin{tabular}{ccccccc}
\hline \multicolumn{9}{c}{ Models $(\mathbf{A}) \&(\mathbf{B})$} & \multicolumn{2}{c}{ Models(A)\&(C) } & \multicolumn{2}{c}{ Models $(\mathbf{B}) \&(\mathbf{C})$} \\
& $\begin{array}{c}\text { Heating } \\
\text { demand } \\
{\left[\mathrm{kWh} / \mathrm{m}^{2} . \mathrm{a}\right]}\end{array}$ & $\begin{array}{c}\text { Cooling } \\
\text { demand } \\
{\left[\mathrm{kWh} / \mathrm{m}^{2} . \mathrm{a}\right]}\end{array}$ & $\begin{array}{c}\text { Heating } \\
\text { demand } \\
{\left[\mathrm{kWh} / \mathrm{m}^{2} . \mathrm{a}\right]}\end{array}$ & $\begin{array}{c}\text { Cooling } \\
\text { demand } \\
{\left[\mathrm{kWh} / \mathrm{m}^{2} . \mathrm{a}\right]}\end{array}$ & $\begin{array}{c}\text { Heating } \\
\text { demand } \\
{\left[\mathrm{kWh} / \mathrm{m}^{2} . \mathrm{a}\right]}\end{array}$ & $\begin{array}{c}\text { Cooling } \\
\text { demand } \\
{\left[\mathrm{kWh} / \mathrm{m}^{2} . \mathrm{a}\right]}\end{array}$ \\
\hline $\mathrm{T}_{\mathbf{H}=20.0^{\circ} \mathrm{C} \& \mathrm{~T}_{\mathbf{C}}=25.0^{\circ} \mathrm{C}}$ & 7.2 & 0.04 & 7.11 & 0.05 & 0.11 & 0.01 \\
$\mathrm{TS}=22.5^{\circ} \mathrm{C}$ & 10.0 & 0.30 & 10.0 & 0.32 & 0.02 & 0.05 \\
\hline
\end{tabular}

To further analyze the influence of the insulation and air tightness level of the building on the heating and cooling demands for models B and C, the models are compared for three different levels of insulation and airtightness. The three levels are documented in

Table 5. Moreover, both temperature setpoint settings are applied with these three different levels.

Table 5: The different groups of parameters varied in the

\begin{tabular}{lccc}
\hline & $\begin{array}{c}\text { Air } \\
\text { tightness } \\
{[1 / \mathrm{h}]}\end{array}$ & $\begin{array}{c}\text { U-value } \\
\text { envelope } \\
{\left[\mathrm{W} / \mathrm{m}^{2} . \mathrm{K}\right]}\end{array}$ & $\begin{array}{c}\text { U-value } \\
\text { glassing } \\
{\left[\mathrm{W} / \mathrm{m}^{2} . \mathrm{K}\right]}\end{array}$ \\
\hline Group (1) & 2.5 & 0.30 & 1.1 \\
Group (2) & 1.3 & 0.24 & 1.0 \\
Group (3) & 0.6 & 0.15 & 0.8 \\
\hline
\end{tabular}

In Table 6 and Table 7, the resulting total yearly heating and cooling demands are documented, for the two setpoint temperature settings respectively. The absolute difference for the heating and cooling demand per square meter for model(B) and (C) was very low at $\mathrm{T}_{\mathrm{S}}\left(22.5^{\circ} \mathrm{C}\right)$. Whereas, the absolute difference of both models at $\mathrm{T}_{\mathrm{H}}\left(20^{\circ} \mathrm{C}\right)$, and $\mathrm{T}_{\mathrm{C}}\left(25^{\circ} \mathrm{C}\right)$ for the different settings were higher regarding the cooling demand in Table 7 however, the cooling loads remain very small since internal gains from occupants, lighting and equipment are not considered.

Next, models (B) and (C) are compared by observing the hourly heating and cooling demands, for the different combinations of insulation, air tightness levels, and setpoint temperatures Figure 8. The normalized root mean square error (NRMSE) is calculated to see the average difference between models (B) and (C) in percentage for the hourly demand. By applying one temperature setting for heating and cooling the NRMSE values between the two model were lower in comparison to applying two different temperature settings for heating and cooling. In terms of the U-values, the lower the U-value the better the fitting of the heating and cooling demand output of models(B) and (C). since there are high heat losses which decreases the chance for the thermal mass to store energy. As it is shown in setting (A) where U-value is $0.30\left[\mathrm{~W} / \mathrm{m}^{2}\right.$. $\mathrm{K}]$ at $\mathrm{T}_{\mathrm{S}}$ the hourly demand difference between models in percentage is low around $1.6 \%$, whereas setting $(\mathrm{F})$ where $\mathrm{U}$-value is $0.15\left[\mathrm{~W} / \mathrm{m}^{2} . \mathrm{K}\right]$ at $\mathrm{T}_{\mathrm{H}}$ and $\mathrm{T}_{\mathrm{C}}$ has higher difference percentage of $14.4 \%$. This is due to the low heat losses from the building to the outside thus, allowing the heat to be stored in the building mass. From this analysis we can see that the differences are bigger for the most insulated buildings, and for the cases with the different set point temperatures. While low differences is obtained with less insulated buildings, with one set temperature.

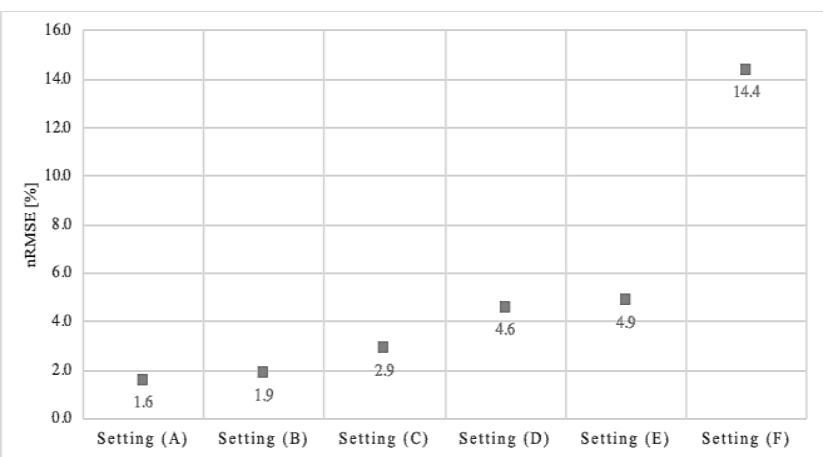

Figure 8: Normalized RMSE-value [\%] of the difference between the simulation data of model $(B)$ and $(C)$ at the different model settings 
Table 6: Comparison between model $(B)$ and $(C)$ at $T_{S}=22.5^{\circ} \mathrm{C}$

\begin{tabular}{ccccccc}
\hline & \multicolumn{2}{c}{ Model (B) } & \multicolumn{2}{c}{ Model (C) } & \multicolumn{2}{c}{ Absolute difference } \\
\hline & $\begin{array}{c}\text { Heating } \\
\text { demand } \\
{\left[\mathrm{kWh} / \mathrm{m}^{2} . \mathrm{a}\right]}\end{array}$ & $\begin{array}{c}\text { Cooling } \\
\text { demand } \\
{\left[\mathrm{kWh} / \mathrm{m}^{2} . \mathrm{a}\right]}\end{array}$ & $\begin{array}{c}\text { Heating } \\
\text { demand } \\
{\left[\mathrm{kWh} / \mathrm{m}^{2} . \mathrm{a}\right]}\end{array}$ & $\begin{array}{c}\text { Cooling } \\
\text { demand } \\
{\left[\mathrm{kWh} / \mathrm{m}^{2} . \mathrm{a}\right]}\end{array}$ & $\begin{array}{c}\text { Heating } \\
\text { Demand } \\
{\left[\mathrm{kWh} / \mathrm{m}^{2} . \mathrm{a}\right]}\end{array}$ & $\begin{array}{c}\text { Cooling } \\
\text { Demand } \\
{\left[\mathrm{kWh} / \mathrm{m}^{2} . \mathrm{a}\right]}\end{array}$ \\
\hline $\begin{array}{c}\text { Setting (A) } \\
\text { U-Value }=\mathbf{0 . 3 0}\end{array}$ & 70.70 & 2.01 & 70.67 & 1.97 & 0.03 & 0.04 \\
$\begin{array}{c}\text { Setting (B) } \\
\text { U-Value }=\mathbf{0 . 2 4}\end{array}$ & 58.90 & 2.06 & 58.86 & 2.01 & 0.04 & 0.05 \\
$\begin{array}{c}\text { Setting (C) } \\
\text { U-Value }=\mathbf{0 . 1 5}\end{array}$ & 16.08 & 3.70 & 16.08 & 3.68 & 0.00 & 0.02 \\
\hline
\end{tabular}

Table 7: Comparison between model $(B)$ and $(C)$ at $T_{H}=20^{\circ} \mathrm{C}$ and $T_{C}=25^{\circ} \mathrm{C}$

\begin{tabular}{|c|c|c|c|c|c|c|}
\hline & \multicolumn{2}{|c|}{ Model (B) } & \multicolumn{2}{|c|}{ Model (C) } & \multicolumn{2}{|c|}{ Absolute difference } \\
\hline & $\begin{array}{c}\text { Heating } \\
\text { demand } \\
{\left[\mathrm{kWh} / \mathrm{m}^{2} . \mathrm{a}\right]}\end{array}$ & $\begin{array}{c}\text { Cooling } \\
\text { demand } \\
{\left[\mathrm{kWh} / \mathrm{m}^{2} . \mathrm{a}\right]}\end{array}$ & $\begin{array}{c}\text { Heating } \\
\text { demand } \\
{\left[\mathrm{kWh} / \mathrm{m}^{2} . \mathrm{a}\right]}\end{array}$ & $\begin{array}{c}\text { Cooling } \\
\text { demand } \\
{\left[\mathrm{kWh} / \mathrm{m}^{2} \cdot \mathrm{a}\right]}\end{array}$ & $\begin{array}{c}\text { Heating } \\
\text { Demand } \\
{\left[\mathrm{kWh} / \mathrm{m}^{2} . \mathrm{a}\right]}\end{array}$ & $\begin{array}{c}\text { Cooling } \\
\text { Demand } \\
{\left[\mathrm{kWh} / \mathrm{m}^{2} . \mathrm{a}\right]}\end{array}$ \\
\hline $\begin{array}{c}\text { Setting }(\mathrm{D}) \\
\text { U-Value }=\mathbf{0 . 3 0}\end{array}$ & 53.39 & 0.02 & 53.55 & 0.03 & 0.16 & 0.01 \\
\hline $\begin{array}{c}\text { Setting }(\mathrm{E}) \\
\text { U-Value }=\mathbf{0 . 2 4}\end{array}$ & 44.10 & 0.03 & 44.26 & 0.05 & 0.16 & 0.02 \\
\hline $\begin{array}{c}\text { Setting }(F) \\
\text { U-Value }=\mathbf{0 . 1 5}\end{array}$ & 10.88 & 0.83 & 10.93 & 1.11 & 0.05 & 0.28 \\
\hline
\end{tabular}

\section{Perspectives}

This paper has shown a methodology for modelling buildings with TABS floors. The building stock model's simulation output such as heating and cooling demand and load duration curves will be used for sizing of hybridGEOTABS systems. In the next steps, we are going to expand the methodology to cover three other typologies: school buildings, elderly homes and multifamily buildings. Then, the methodology will be applied on a larger set of buildings, representing the European building stock for these four typologies within the different climatic zones appearing in Europe.

\section{Conclusions}

In this paper, a methodology is developed and validated for multi-zone BES-modelling of the offices building stock starting from general geometrical data. One aspect of the approach is the fitting of real building geometry to the geometry of an office building, starting from general geometrical. A second aspect of the approach is the splitting of the BES-model into models for the different modules (floors) that can be simulated are combined faster than modelling the entire building. The assumption is that the floors are thermally separated anyway, if they are TABS floors. The validation of this approach is explained and discussed.

It is concluded that by using one set temperature, a lower absolute difference of less than $1 \mathrm{kWh} / \mathrm{m}^{2} /$ year between models (B) and (C) is achieved thus the new modelling approach can be used for modelling the whole building stock of offices.

This approach will further be explored and applied to simulate heating and cooling demands for the purpose of evaluating the feasibility and performance of hybridGEOTABS technology in the EU building stock for offices, elderly homes, multi-family buildings and schools.

\section{Acknowledgement}

This research is part of the hybridGEOTABS project, that has received funding from the European Union's Horizon 2020 research and innovation programme under grant agreement No 723649 (MPC-GT).

The authors are also thankful to the Flemish Energy Agency (VEA) for the building stock database.

\section{References}

Baetens, R., De Coninck,, R., Jorissen, F., Picard, D., Helsen, L. and Saelens, D. (2015). OpenIDEAS - An Open Framework for Integrated District Energy Simulations. In: 14th Conference of International Building Performance Simulation Association. [online] Hyderabad: IBPSA, pp.347 - 354. Available at:http://www.ibpsa.org/proceedings/BS2015/p2243. pdf [Accessed 2 Feb. 2019].

Ballarini, I., Corgnati, S. and Corrado, V. (2014). Use of reference buildings to assess the energy saving potentials of the residential building stock: The experience of TABULA project. Energy Policy, 68, pp.273-284.

Cupeiro figueroa, I., Drgon, J., Picard, D., Abdollahpouri, M. and Helsen, L. (2018). State observers for optimal control using white-box building models. In: Purdue Conferences - 5th International High Performance Building Conference. West Lafayette: Purdue University.

Dascalaki, Elena G., Kalliopi G. Droutsa, Constantinos A. Balaras, and Simon Kontoyiannidis. (2011). "Building typologies as a tool for assessing the energy performance of residential buildings - A case study 
for the Hellenic building stock." Energy and Buildings 3400-3409.

Delghust, M., Strobbe, T., De Meyer, R. and Janssens, A. (2015). Enrichment of single-zone EPB-data into multizone modles using BIM-based parameteric typologies. In: 14th International Conference of IBPSA: Building Simulation. ed.Jyotirmay Mathur and Vishal Garg,IIIT Hyderabad and IBPSA, Hyderabad, India.

HybridGeotabs Project (2016-2020). Accessed April 2019. http://www.hybridgeotabs.eu.

Kavgic, M., Mavrogianni, A., Mumovic, D., Summerfield, A., Stevanovic, Z. and DjurovicPetrovic, M. (2010). A review of bottom-up building stock models for energy consumption in the residential sector. Building and Environment, 45(7), pp.1683-1697.

Neufert, Ernst. (2000). Neufert Architects' Data, Third Edition. Wiley-Blackwell.

Sandberg, Nina Holck, Igor Sartori, Oliver Heidrich , and Richard Dawson. 2016. "Dynamic building stock modelling: Application to 11 European countries to support the energy efficiency and retrofit ambitions of the EU." Energy and Buildings 132: 26-38

Shorrock, L. and Dunster, J. (1997). The physically-based model BREHOMES and its use in deriving scenarios for the energy use and carbon dioxide emissions of the UK housing stock. Energy Policy, 25(12), pp.10271037.

Tuominen, P., Holopainen, R., Eskola, L., Jokisalo, J. and Airaksinen, M. (2014). Calculation method and tool for assessing energy consumption in the building stock. Building and Environment, 75, pp.153-160.

VEA-EPB database. 2016. "EPB database gathered till end 2016, VEA (Flemish Energy Agency)." https://www.energiesparen.be/over_vea.

Wang, D., Landolt, J., Mavromatidis, G., Orehounig, K. and Carmeliet, J. (2018). CESAR: A bottom-up building stock modelling tool for Switzerland to address sustainable energy transformation strategies. Energy and Buildings, 169, pp.9-26. 